Proceedings

\title{
Exposure of Tribolium castaneum (Herbst) (Coleoptera: Tenebrionidae) Females to Spinosad: Effect on the Fitness of Their Progeny ${ }^{\dagger}$
}

\author{
Anna Skourti *, Nickolas G. Kavallieratos, Nikos E. Papanikolaou
}

Citation: Skourti, A.; Kavallieratos, N.G.; Papanikolaou, N.E. Exposure of Tribolium castaneum (Herbst) (Coleoptera: Tenebrionidae) Females to Spinosad: Effect on the Fitness of Their Progeny, in Proceedings of the 1st International Electronic Conference on Entomology, 1-15 July 2021, MDPI: Basel, Switzerland, doi:10.3390/IECE-10396

Published: 30 June 2021

Publisher's Note: MDPI stays neutral with regard to jurisdictional claims in published maps and institutional affiliations.

Copyright: (c) 2021 by the authors. Submitted for possible open access publication under the terms and conditions of the Creative Commons Attribution (CC BY) license (http://creativecommons.org/licenses/by/4.0/).
Laboratory of Agricultural Zoology and Entomology, Department of Crop Science, Agricultural University of Athens, 75 Iera Odos str., 11855, Athens, Attica, Greece; annaskourti@aua.gr (A.S.); nick_kaval@aua.gr (N.G.K.); nikosp@aua.gr (N.E.P.)

* Correspondence: annaskourti@aua.gr

+ Presented at the 1st International Electronic Conference on Entomology (IECE 2021), 1-15 July 2021; Available online: https://iece.sciforum.net/.

\begin{abstract}
The red flour beetle, Tribolium castaneum (Herbst) (Coleoptera: Tenebrionidae) is a widespread pest of stored products. While the direct effects of several pesticides have been evaluated on this notorious species, little is known on their indirect effects in terms of progeny fitness. In this study, we investigated the cost of different exposure intervals of T. castaneum females to spinosad by calculating the life table parameters of its progeny. For this purpose, females of T. castaneum were exposed for 5, 10 and $20 \mathrm{~min}$ to spinosad and birth or death rates of progeny were estimated. Water was used as a control treatment. The mean values of the net reproductive rate, the intrinsic rate of increase, the finite rate of increase, the mean generation time and the doubling time of the control treatment were 6.3 females/female, 0.029 females/female/day, 1.029, 63.6 days and 24.1 days, respectively, which are indicative of the potential population increase of T. castaneum. When female parental time exposure to spinosad was 5, 10 and $20 \mathrm{~min}$, the corresponding values were $0.073,0.135$ and 0.097 females/female; $-0.045,-0.031$ and -0.048 females/female/day; 0.956, 0.970 and 0.953; 60.6, 67.7; and 50.3 days; $-15.9,-23.3$ and -14.8 days, respectively, which indicate a population decrease. However, based on the $95 \%$ confidence intervals criterion, the different exposure intervals of $T$. castaneum females to spinosad did not affect the fitness of their progeny. These results may have bearing on the management of T. castaneum in storage facilities.
\end{abstract}

Keywords: red flour beetle; demography; pest management; intrinsic rate of increase; spinosad

\section{Introduction}

The red flour beetle, Tribolium castaneum (Herdst) (Coleoptera: Tenebrionidae) is a notorious stored-product species with global distribution [1]. It infests several commodities such as cereal grains, nuts, spices, chocolate, cacao, dried fruits and animal products [2]. A common method to reduce T. castaneum infestations in stored-products is the application of insecticides [3,4,5]. However, due to the economic importance of this species, as well as its tolerance to several insecticides [4], a precise evaluation of the management strategies seems imperative and important for its control.

Demography is an efficient tool in order to elucidate insect fitness components. Tabulating birth and death rates, several parameters can be calculated that are indicative of the potential population increase of species. This method is appropriate in for the estimation of time-varying processes such as insect survival and reproduction through time [4] and has been widely used in order to evaluate the potential population increase of insects $[6,7,8,9]$. However, it is rarely applied to evaluate the efficacy of insecticides $[4,5,10]$. 
Therefore, aim of this study is to explore possible indirect effects of spinosad on $T$. castaneum. For this purpose, we investigated the cost of different exposure times of parental T. castaneum females to spinosad on the fitness of the progeny, based on the resulting demographic parameters. We adopted a recently proposed demographic approach that is suitable to explore the indirect effects of insecticides [10].

\section{Materials and Methods}

Females of T. castaneum were exposed for 5, 10 and $20 \mathrm{~min}$ to spinosad, while water was used as a control treatment. Groups of eggs laid by these females (150 eggs per exposure time to spinosad and 80 for the control treatment) were placed separately in Petri dishes, without food, and then transferred into an incubator set at $30^{\circ} \mathrm{C}, 65 \%$ relative humidity and continuous darkness. Dishes were inspected daily to assess larval emergence. The newly emerged larvae were separately transferred to new dishes with soft wheat flour. The lids of dishes had a central circular opening (covered by muslin cloth) to allow the aeration of the content. Mortality of immatures was inspected daily. Pairs of newly emerged adults were separately transferred to new dishes that contained soft wheat flour. The adult mortality and female fecundity were recorded every $24 \mathrm{~h}$ until all individuals became dead.

Using the above data, the following demographic parameters were calculated [11]: the net reproductive rate: $R_{0}=\sum\left(l_{x} \times m_{x}\right)$, where $l x$ denotes the age-specific survival and $m_{x}$ the age-specific fecundity, i.e., the per capita rate of progeny production in an interval equal to cohort study interval; the intrinsic rate of increase $\left(r_{m}\right)$ : $\sum\left(e^{r_{m} \times x} \times l_{x} \times m_{x}\right)=1$, i.e., the rate of natural increase in a closed population (subjected to constant age-specific schedules of fertility and mortality for a long period); the finite rate of increase: $\lambda=e^{r_{m}}$, i.e., the rate at which the population will increase in each time step; the mean generation time: $T=\frac{\ln R_{0}}{r_{m}}$, i.e., the time required for the population to increase by a factor equal to the net reproductive rate; the doubling time: $D T=\frac{\ln 2}{r_{m}}$, i.e., the time required for the population to double. In addition, the $95 \%$ confidence intervals of all the calculated parameters were obtained by bootstrapping in $\mathrm{R}$ [12].

\section{Results}

The estimated demographic parameters are presented in Table 1. The values of the net reproductive rate, the intrinsic rate of increase, the finite rate of increase, the mean generation time and the doubling time of the control treatment were 6.3 females/female, 0.029 females/female/day, 1.029, 63.6 days and 24.1 days, respectively. When parental females were exposed for $5 \mathrm{~min}$ to spinosad, the values of the net reproductive rate, the intrinsic rate of increase, the finite rate of increase and the doubling time were significantly lower, i.e., 0.073 females/female, -0.045 females/female/day, 0.956 and -15.9 days, respectively, while the estimated mean generation time did not differ significantly (60.6 days). An increase to the parental exposure time did not further affect $T$. castaneum demographic parameters. Thus, the estimated net reproductive rate was 0.135 and 0.097 females/female, the intrinsic rate of increase -0.031 and -0.048 females/female/day, the finite rate of increase 0.970 and 0.953 , the mean generation time 67.7 and 50.3 days and the doubling time -23.3 and -14.8 days when parental females were exposed for 10 and $20 \mathrm{~min}$ to spinosad, respectively. 
Table 1. Values of net reproductive rate $\left(R_{0}\right)$, intrinsic rate of increase $\left(r_{m}\right)$, finite rate of increase $(\lambda)$, mean generation time $(T)$ and doubling time $(D T)$ of $T$. castaneum (mean, $95 \%$ confidence intervals) at several exposure times of parental female to spinosad.

\begin{tabular}{cccccc}
\hline $\begin{array}{c}\text { Exposure } \\
\text { (min) }\end{array}$ & $\begin{array}{c}\boldsymbol{R}_{\boldsymbol{0}} \\
\text { (females/female) }\end{array}$ & $\begin{array}{c}\boldsymbol{r}_{m} \\
\text { (females/female/day) }\end{array}$ & $\lambda$ & $\begin{array}{c}\boldsymbol{T} \\
\text { (days) }\end{array}$ & $\begin{array}{c}D T \\
\text { (days) }\end{array}$ \\
\hline \multirow{2}{*}{0} & $6.3 \mathrm{a}$ & $0.029 \mathrm{a}$ & $1.029 \mathrm{a}$ & $63.6 \mathrm{a}$ & $24.1 \mathrm{a}$ \\
& $(4.8-8.1)$ & $(0.024-0.033)$ & $(1.024-1.034)$ & $(61.7-66.0)$ & $(20.9-28.8)$ \\
5 & $0.073 \mathrm{~b}$ & $-0.045 \mathrm{~b}$ & $0.956 \mathrm{~b}$ & $60.6 \mathrm{ab}$ & $-15.9 \mathrm{~b}$ \\
& $(0.027-0.127)$ & $(-0.063-0.033)$ & $(0.939-0.968)$ & $(53.2-67.5)$ & $(-21.0--11.1)$ \\
& $0.135 \mathrm{~b}$ & $-0.031 \mathrm{~b}$ & $0.970 \mathrm{~b}$ & $67.7 \mathrm{ab}$ & $-23.3 \mathrm{~b}$ \\
& $(0.043-0.241)$ & $(-0.046-0.021)$ & $(0.955-0.979)$ & $(55.8-77.7)$ & $(-32.4--15.1)$ \\
& $0.097 \mathrm{~b}$ & $-0.048 \mathrm{~b}$ & $0.953 \mathrm{~b}$ & $50.3 \mathrm{~b}$ & $-14.8 \mathrm{~b}$ \\
& $(0.028-0.197)$ & $(-0.068-0.034)$ & $(0.935-0.966)$ & $(45.0-55.8)$ & $(-20.2--10.2)$ \\
\hline
\end{tabular}

Means in the same column followed by different letters are significantly different.

\section{Discussion}

Our study clearly shows that $T$. costaneum female exposure to spinosad is associated with differences in the performance of their progeny. All the tested exposure intervals of T. castaneum females to spinosad had detrimental effects to the fitness of their progeny. This is due to the negative values of the intrinsic rate of increase and the doubling time, as well as the lower to 1 estimates of the net reproductive rate and the finite rate of increase, which indicate a continuous population decrease in all cases. This further means that in all treatments, spinosad is highly efficient against $T$. castaneum in terms of offspring survival and reproduction. Although this insecticide did not have a direct effect on the parental T. castaneum population, as a consequence of direct toxicity or through delayed mortality, we showed that its offspring production will suffer serious effects that could lead to the extinction of their colonies. This is particularly important for the management of this species and should be taken into account as it could reduce the insecticide applications. Similar results have been reported by Skourti et al. [4], as they stated that the fitness of the progeny of $T$. costaneum is seriously affected when parental females were exposed to pirimiphos-methyl.

The demographic approach we followed in this study allowed us to investigate the indirect effects of spinosad on the progeny of $T$. castaneum females, by tabulating their birth and death rates. This methodology is particularly useful for highlighting the effectiveness of the insecticides, accounting for time-varying effects. We expect future studies to shed light into the indirect effects of insecticides on stored-product insect pests taking advantage of this method, in order to gather together more information on their efficacy.

Author Contributions: Conceptualization, A.S., N.G.K. and N.E.P.; methodology, A.S., N.G.K. and N.E.P.; validation, A.S., N.G.K. and N.E.P.; formal analysis, N.E.P.; investigation, A.S.; resources, N.G.K.; data curation, N.E.P.; writing-original draft preparation, A.S., N.G.K. and N.E.P.; writing - review and editing, A.S., N.G.K. and N.E.P.; supervision, N.G.K.; funding acquisition, A.S. and N.G.K. All authors have read and agreed to the published version of the manuscript.

Funding: This research was funded by the State Scholarships Foundation (2018-050-0502-11763).

Institutional Review Board Statement: Not applicable.

Informed Consent Statement: Not applicable.

Data Availability Statement: Data is contained within the article.

Conflicts of Interest: The authors declare no conflict of interest. The funders had no role in the design of the study; in the collection, analyses, or interpretation of data; in the writing of the manuscript, or in the decision to publish the results. 


\section{References}

1. Rees, D. Insects of stored products. Manson Publishing, London, 2004.

2. Hagstrum, D.W.; Klejdysz, T.; Subramanyam, Bh.; Nawrot, J. Atlas of stored-product insects and mites. AACC International, St Paul, MN, 2013.

3. Kavallieratos, N.G.; Nika, E.P.; Skourti, A.; Ntalli, N.; Boukouvala, M.C.; Ntalaka, C.T.; Maggi, F.; Rakotosaona, R.; Cespi, M.; Perinelli, D.R.; Canale, A.; Bonacucina, G.; Benelli, G. Developing a Hazomalania voyronii essential oil nanoemulsion for the ecofriendly management of Tribolium confusum, Tribolium castaneum and Tenebrio molitor larvae and adults on stored wheat. Molecules 2021, 26, 1812.

4. Skourti, A.; Kavallieratos, N.G.; Papanikolaou, N.E. Exposure of Tribolium castaneum (Herbst) females to pirimiphos-methyl alters the fitness of their progeny. Env. Sci. Poll. Res., 2021, 28, 7893-7900.

5. Skourti, A.; Kavallieratos, N.G.; Papanikolaou, N.E. How is fitness of Tribolium castaneum (Herbst) (Coleoptera: Tenebrionidae) affected when different developmental stages are exposed to chlorfenapyr? Insects 2020, 11, 542.

6. Kavallieratos, N.G.; Andrić, G.; Pražić Golić, M.; Nika, E.P.; Skourti, A.; Kljajić, P.; Papanikolaou, N.E. Biological features and population growth of two Southeastern European Tribolium confusum Jacquelin du Val (Coleoptera: Tenebrionidae) strains. Insects 2020, 11, 218.

7. Skourti, A.; Kavallieratos, N.G.; Papanikolaou, N.E. Suitability of semolina, cracked wheat and cracked maize as feeding commodities for Tribolium castaneum (Herbst; Coleoptera: Tenebrionidae). Insects 2020, 11, 99.

8. Kavallieratos, N.G.; Karagianni, E.S.; Papanikolaou, N.E. Life history of Trogoderma granarium Everts (Coleoptera: Dermestidae) on peeled barley, peeled oats and triticale. J. Stored Prod. Res. 2019, 84, 101515.

9. Papanikolaou, N.E.; Kavallieratos, N.G.; Kondakis, M.; Boukouvala, M.C.; Nika, E.P.; Demiris, N. Elucidating fitness components of the invasive dermestid beetle Trogoderma granarium combining deterministic and stochastic demography. PLoS ONE 2019, 14, e0212182

10. Stark, J.D., Banks, J.E. Developing demographic toxicity data: optimizing effort for predicting population outcomes. PeerJ, 2016, 4, e2067

11. Carey, J.R. Applied demography for biologists with special emphasis on insects. Oxford University Press, New York, NY, 1993.

12. R Core Team. R: A language and environment for statistical computing. R Foundation for statistical computing, 2020, Vienna. http://www.r-project.org. 